\title{
Репродуктивный потенциал Lonicera L. (Caprifoliacea Juss.) при интродукции
}

\section{Reproductive potential of Lonicera L. (Caprifoliacea Juss.) in introduction}

\author{
Киселёва Т. И. \\ Kiseleva T. I. \\ 2. Новосибирск, Россия. E-mail: tk552008@yandex.ru \\ Novosibirsk, Russia
}

\begin{abstract}
Peфepam. Приведены результаты исследования завязываемости семян 13 видов Lonicera L. коллекции Центрального сибирского ботанического сада (г. Новосибирск). Выявлено потенциальное и фактическое число семян в одном плоде. Интродуценты демонстрируют высокий показатель завязываемости и значительное варьирование числа семян в плодах.
\end{abstract}

Ключевые слова. Жимолость, завязываемость семян, число семян, интродукция, инвазия.

Summary. The results of the study of seed formation of 13 Lonicera L. species in the collection of Central Siberian Botanical Garden in Novosibirsk are presented. Potential and real quantity of seeds in a fruit was revealed. Introductions show a high level of seed formation and substantial variation of seeds quantity in fruits.

Key words. Lonicera, formation of seeds, quantity of seeds, introduction, invasion

K роду Lonicera L. семейства Caprifoliaceae Juss. относится более 200 видов. Многие представители рода имеют большую практическую ценность и рекомендуются как для озеленения поселений за высокие декоративные качества (Аксенов, Аксенова, 1997), так и для использования в качестве подлеска в лесопарках, пригородных лесах, в полезащитных полосах (Древесные ..., 2008), где могут являться кормовой базой (Заборовский, 1962; Усенко, 1984) и местом гнездования мелких лесных птиц. Использовать некоторые виды жимолости в озеленении (ландшафтном дизайне) рекомендуется в групповых и линейных посадках как свободнорастущих, так и формованных (живые изгороди) из-за их способности к разрастанию кустов в результате образования стеблевой поросли и поросли от корневой шейки (Лучник, 1960).

Интродукцией жимолостей в Центральном сибирском ботаническом саду (ЦСБС) занимаются с 1956 г. За 62 года было вовлечено в интродукционный эксперимент 25 видов Lonicera (Встовская, Коропачинский, 2005). В настоящее время в коллекции содержится 22 вида из разных природно-климатических условий. Растения ежегодно цветут и плодоносят (Интродукция ..., 2017), 10 видов рекомендованы к использованию в озеленении г. Новосибирска (Древесные ..., 2008). В современной интродукции остается задача изучения особенностей биологии размножения растений в новых условиях (Коропачинский, 2005), что можно оценить только в процессе культивирования. Проблему репродукции следует рассматривать и с точки зрения возможных инвазий (Dawson et al., 2008; Яценко, Виноградова, 2018), для чего необходимо проводить оценку риска инвазивной активности чужеродных видов. В этой связи работа по изучению репродуктивного потенциала представителей рода Lonicera сохраняет актуальность.

Плод жимолостей - ягода с сочным мезокарпием, формируется из двух-трехгнездной нижней или полунижней завязи (Пояркова, 1958). В каждом гнезде закладывается по две семяпочки, однако полного развития достигают не все, поэтому число семян колеблется от 1 до 3(6) (Заборовский, 1962). 
Сведений о числе семян, формирующихся в плодах жимолости в природных условиях, крайне мало, чаще при описании вида отмечается размер и форма плодов и семян, и только для трех видов (L. maackii (Rupr.) Maxim., L. ruprechtiana Regel, L. xylosteum L.) из 13-ти, представленных в нашей работе, указывается число семян в плодах (Пояркова, 1958; Заборовский, 1962; Усенко, 1984; Сравнительная ..., 2000; Коропачинский, Встовская, 2012). Определено число семян в плодах видов жимолости из коллекции ГБС (Некрасов, 1973). В ЦСБС также изучали завязываемость семян и есть данные по 5 видам p. Lonicera секции Isika Rehd., в аспекте изменчивости по числу завязей и семяпочек (Романюк, 1985). Цель нашей работы - изучение и оценка завязываемости семян как одного из показателей репродуктивного потенциала видов р. Lonicera при интродукции в климатических условиях лесостепного Приобья.

В работе исследованы плоды 13 видов рода Lonicera коллекции ЦСБС. Коллекция жимолостей размещена на лесной поляне, в опушке смешанного леса. Растения расположены группами по 3-12 экземпляров на расстоянии 2-10(30) м друг от друга. Возрастной состав коллекции разнообразный (от 13 до 52 лет), но большая часть старше 40 лет. Плоды собраны в 2018 г., у L. involucrata (Richards.) Banks в 2013 и 2018 гг. с южной стороны кустов в период созревания, по 15-37 отдельных ягод каждого вида. Сбор плодов и количественную оценку семеношения проводили согласно методическим указаниям (Методические ..., 1980). Особенности завязываемости семян в плодах исследовали визуально и с помощью микроскопа МСП-1. Статистическая обработка опытных данных проведена в редакторе MS EXCEL 2010.

Названия видов приведены в соответствии с базой данных “The Plant List” (The Plant List, 2019). L. pallasii Ledeb. мы рассматриваем как одну из мелких рас L. coerulea L. (Интродукция ..., 2017). L. gibbiflora (Rupr.) Dipp. представлена как самостоятельный вид (Пояркова, 1958). Подроды, секции и подсекции приведены по А. Редеру (ссылка на источник) с небольшими изменениями Рябовой Н. В. (Рябова, 1980).

Из рассматриваемых нами 13-ти видов 50 \% распространены в районах Российского Дальнего Востока, Японии, Китая, $14 \%$ - Северной Америки, $14 \%$ - Средней Европы, 7 \% - Сибири и $21 \%$ - в Европе и Сибири, т. е. 79 \% культивируемых видов являются чужеродными.

В таблице 1 приведен перечень исследуемых видов р. Lonicera из коллекции ЦСБС, где указан интродукционный центр откуда поступил образец, год поступления в коллекцию, современный возраст и число растений в группе, время сбора плодов. Приводятся имеющиеся литературные сведения о числе семян в одном плоде и природный ареал (Заборовский, 1951; Пояркова, 1958; Зайцев, Шульгина, 1962; Усенко, 1984).

В результате исследований выявлен высокий показатель завязываемости семян Lonicera - от 67 до $100 \%$ (табл. 2), только один из образцов L. ruprechtiana показал умеренную завязываемость семян - 40,9 \%, что может быть связано с ослабленностью растений в образце и повреждением завязей насекомыми-вредителями, которые были обнаружены в плодах. Максимальное число семяпочек закладывается у L. pallasii (секция Isika, подсекция Caeruleae Rehd.) - 16 шт., минимальное - 4 у L. glehnii (секция Isika, подсекция Alpigenae Rehd.) (табл. 2). Максимальное число завязавшихся семян в одном плоде L. gibbiflora, L. glehnii, L. maximowiczii, L. nigra коллекции ЦСБС сопоставимо с данными ГБС, у остальных жимолостей коллекции семян завязывается больше, чем при интродукции в Москве, что может указывать на положительную реакцию чужеродных видов на климатические условия Новосибирска, однако растения, выращенные из семян, полученных в культуре, продуцируют семян меньше, чем родительские экземпляры, либо столько же (табл. 3). Почти у всех представленных в работе видов определяется значительное варьирование как числа семяпочек (коэффициент вариации $\mathrm{V}=33-63$ \%), так и числа завязавшихся семян в одном плоде, за исключением L. maackii (незначительный коэффициент вариации - 19 \%). Высока степень неоднородности в завязываемости семян (табл. 3). Наблюдается большой разброс по количеству семян: от 1 до 14 у L. involucrata u L. pallasii, от 1 до 10-11 у L. chrysantha, L. maximowiczii u L. nigra, поэтому здесь среднее значение не является информативным параметром. Так $25 \%$ плодов L. demissa завязывают по 4 семени, при возможных 1-6 (среднее значение 3,2 \pm 0,26), у L. alpigena 31,6 \% по 4 из 1-6 возможных (среднее значение $2,7 \pm 0,33$ ), у L. maackii $56 \%$ по 5 семян из 3-5 возможных (среднее значение $4,4 \pm 0,16$ ). Завязываемость семян по годам варьирует, что подтверждают данные по L. involucrata (табл. 3). 


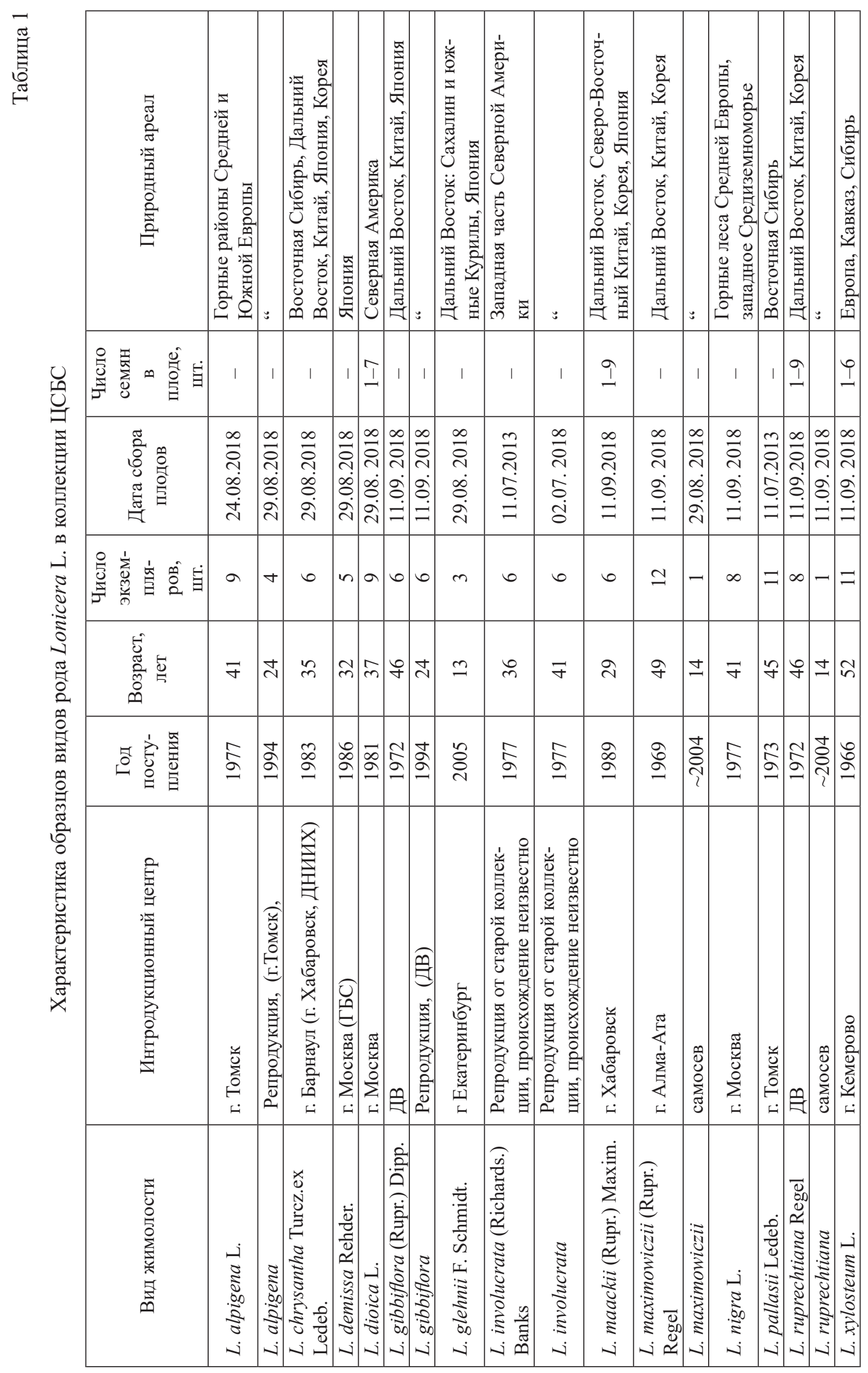


沓

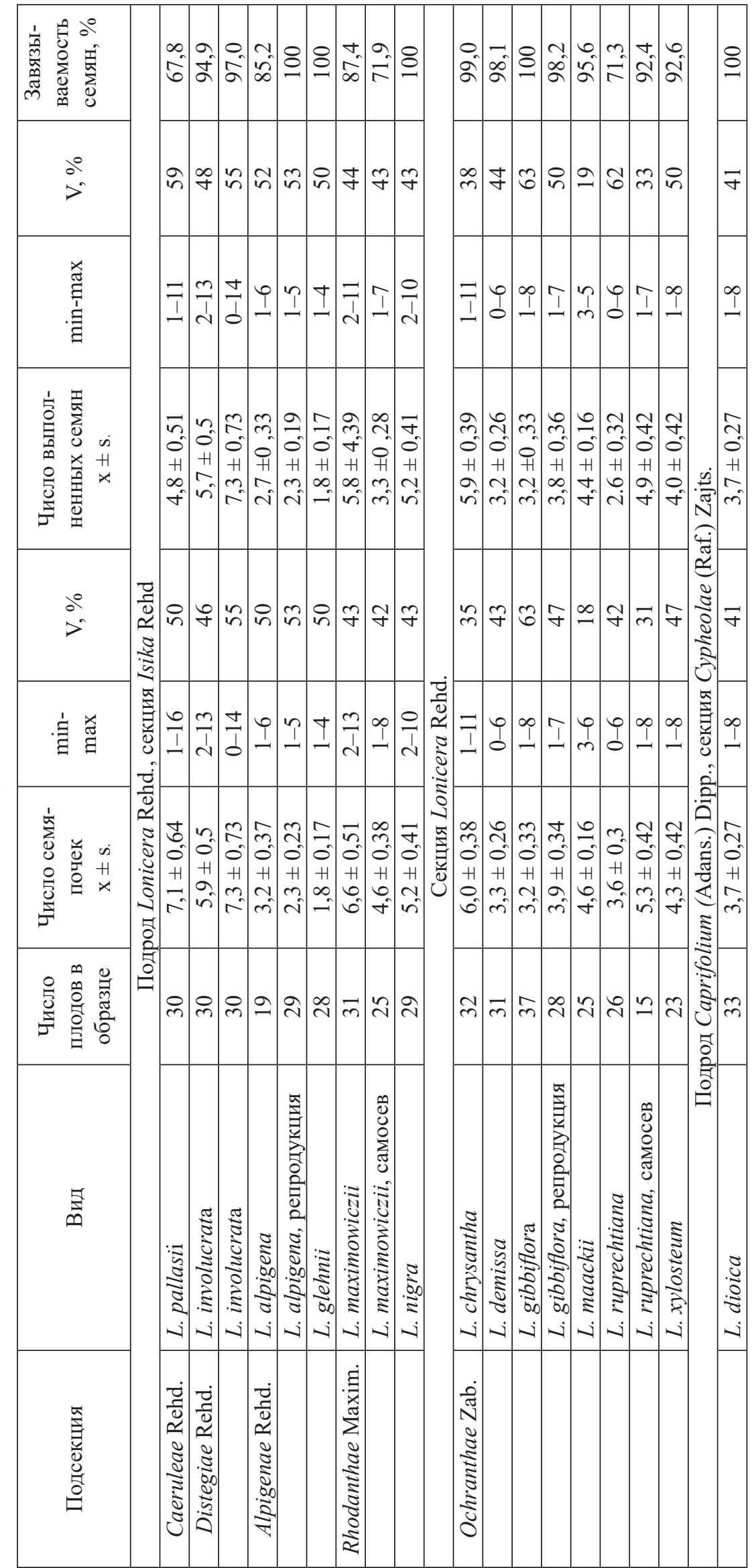




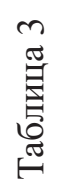

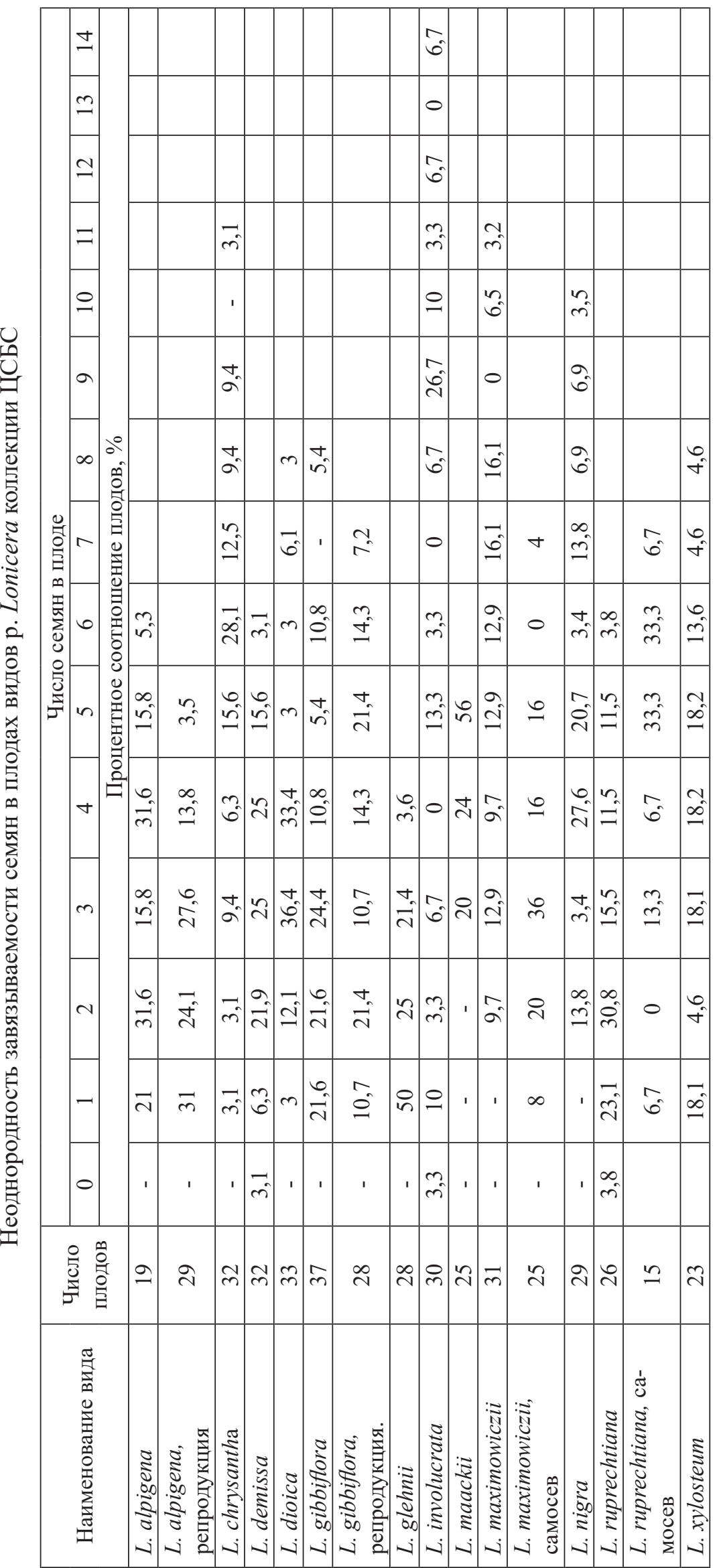


Н. В. Усенко (1984) отмечает, что в природе на Дальнем Востоке плоды L. maackii и L. maximowiczii склевываются птицами. Можно предположить, что при интродукции птицы также могут быть разносчиками семян этих видов жимолости. На территории дендрария ЦСБС и в его окрестностях не установлено явление массового самосева жимолости. Найдено только два экземпляра плодоносящего самосева L. maximowiczii. У L. maackii самосева не обнаружено. Кроме того, у L. demissa, L. ruprechtiana, L. involucrata обнаружено проявление партенокарпии (табл. 2, 3).

Таким образом, результаты исследования завязываемости семян показали достаточно высокую репродуктивную способность как местных, так и чужеродных видов р. Lonicera, демонстрирующую хорошую адаптивную реакцию растений, обеспечивающую воспроизводство в условиях культуры. Растения имеют умеренный самосев, не проявляя инвазионного потенциала.

В статье использовались материалы УНУ «Коллекции живых растений в открытом и закрытом грунте», USU_440534 (экспозиция дендрарий).

\section{ЛИТЕРАТУРА}

Аксенов $\boldsymbol{E}$. $\boldsymbol{C}$., Аксенова Н. А. Декоративные растения. Т. 1. (Деревья и кустарники). Энциклопедия природы России. - М., 1997. -560 с.

Встовская Т. Н., Коропачинский И. Ю. Древесные растения Центрального сибирского ботанического сада. Новосибирск: Изд-во СО РАН, филиал «Гео», 2005. - С. 32-35.

Древесные растения для озеленения Новосибирска / под общей ред. И. Ю. Коропачинского. - Новосибирск: Акад. изд-во «Гео», 2008. - 303 с.

Заборовский $\boldsymbol{E}$. П. Плоды и семена древесных и кустарниковых пород. - М.: Гослесбумиздат, 1962. - С. 256 258.

Интродукция древесных растений в Сибири. 2-е изд., перераб. и доп. / науч. ред. И. Ю. Коропачинский. - Новосибирск: Академическое изд-во «Гео», 2017. - С. 225-243.

Зайцев Г. Н., Шульгина В. В. Род Жимолость - Lonicera L. // Деревья и кустарники CCCР. - М.-Л.: изд-во Акад. наук, 1962. - С. 211-299.

Коропачинский И. Ю. О задачах российской дендрологии в XXI веке // Сибирский экологический журнал, №4. Изд-во СО РАН. - Новосибирск. 2005. - С. 541 - 561.

Коропачинский И. Ю., Встовская Т. Н. Древесные растения Азиатской России. 2-е изд. - Новосибирск: Академическое изд-во «Гео», 2012. - С. 408-420.

Лучник 3. И. Обрезка кустарников. - М.: Гос. изд. сельхоз. литературы, 1960. - 96 с.

Некрасов В. И. Основы семеноведения древесных растений при интродукции. - М.: Наука, 1973. - 268 с.

Пояркова А. И. Сем. Жимолостные - Caprifoliacea Vent. // Флора СССР. - М.-Л.: изд-во Акад. наук, 1958. - Т. 23. - C. 467-573.

Романюк В. В. Биология семеношения и прорастания семян интродуцируемых в лесостепной зоне Западной Сибири видов рода Жимолость: автореф. ... канд. биол. наук. - Новосибирск, 1985. - 16 с.

Методические указания по семеноведению интродуцентов. - М.: Наука, 1980. -63 с.

Рябова Н. В. Жимолость. Итоги интродукции в Москве. - М.: Наука, 1980. - 160 с.

Сравнительная анатомия семян. Т. 6. Двудольные. Rosidae II. // Ред. А. Л. Тахтаджян. - СПб.: Наука, 2000. C 367-378.

Усенко Н. В. Деревья, кустарники и лианы Дальнего Востока. Справочная книга. Второе, переработанное и дополненное издание. - Хабаровск: Кн. изд-во, 1984. - С. 215 -221.

Яценко И. О., Виноградова Ю. К. Инвазионная активность древесных растений в Главном ботаническом саду им. Н. В. Цицина Российской Академии наук // Российский журнал биологических инвазий, 2018. - № 4. - С. $117-131$.

Dawson W., Mndolwa A. S., Burslem D., Hulme P. E. Assessing the risks of plant invasions arising from collections in tropical botanical gardens // Biodiversity Conservation, 2008. - Vol. 17. - P. 1979-1995.

The Plant List. URL: http://www.theplantlist.org (Дата обращения 19.02.2019). 